\title{
Spatiotemporal prediction of soil moisture content using multiple-linear regression in a small catchment of the Loess Plateau, China
}

\author{
Yang Qiu ${ }^{\mathrm{a}, \mathrm{b}}$, Bojie $\mathrm{Fu}^{\mathrm{a}, *}$, Jun Wang ${ }^{\mathrm{c}}$, Liding Chen ${ }^{\mathrm{a}}$ \\ ${ }^{a}$ Department of Systems Ecology, Research Center for Eco-Environmental Sciences, \\ Chinese Academy of Sciences, P.O. Box 2871, Beijing 100085, China \\ ${ }^{\mathrm{b}}$ Department of Resources and Environmental Sciences, Beijing Normal University, Beijing 100875, China \\ ${ }^{\mathrm{c}}$ Land Consolidation and Rehabilitation Center, Ministry of Land and Resources, Beijing 100035, China
}

\begin{abstract}
Three basic multiple-linear regression models with different sets of more readily observed environmental variables (land use, topographic and meteorological factors) were developed for the prediction of soil moisture content in space and time. The model performances were evaluated in the Danangou catchment $\left(3.5 \mathrm{~km}^{2}\right)$ on the Loess Plateau, China, with soil moisture content measurements. The soil moisture content measurements were performed biweekly at five depths in the soil profile $(0-5,10-15,20-25,40-45$ and $70-75 \mathrm{~cm})$ from May to October 1998 and from May to September 1999, using a Delta-T theta probe. It was indicated that the regression models could describe the relationships of soil moisture content with environmental attributes. It was found that the spatiotemporal-SM model showed the best goodness of fit since it explained the greatest fraction of soil moisture variation in both space and time, and the predicted mean, standard deviation, minimum and maximum soil moisture were closest to the observed values. This model was also either the most precise or the most economical in prediction of soil moisture content in space and time since it gives the lowest values in mean absolute error of prediction (MAE) and Akaike information criterion (AIC). There is little difference in performance and cost-benefit between the spatial-GM model and landuse-GM model. The superior robustness of the spatiotemporal-SM model over the other two models is most significant in the prediction of soil moisture content at $0-5 \mathrm{~cm}$, and decreases with increasing soil depth.
\end{abstract}

(C) 2003 Elsevier Science B.V. All rights reserved.

Keywords: Soil moisture content; Spatiotemporal prediction; Multiple-linear regression; Environmental attributes; The Loess Plateau of China

* Corresponding author. Fax: +86-10-62943840.

E-mail address: bfu@mail.rcees.ac.cn (B. Fu). 


\section{Introduction}

Soil moisture content is an important variable for understanding and predicting a range of hydrological processes. The prediction of soil moisture content distribution in space and time is difficult though necessary for soil and land survey (Webster and Butler, 1976; McKenzie and Austin, 1993), soil and land evaluation (Fu, 1991; Fu and Gulinck, 1994; Fu et al., 2000; Chen et al., 2003), hydrologic modeling and watershed management (Western et al., 1999; Qiu et al., 2001a,b). For instance, antecedent soil moisture content is one of the most important parameters of a hydrological model, since it influences the amount of infiltration and the vertical movement of water in the soil and, therefore, affects the amount of runoff (Hawley et al., 1983; De Roo et al., 1996; Georgakakos and Baumer, 1996).

There are three ways to estimate soil moisture content. The first builds on local soil moisture classification; the second uses direct interpolation of data from field site; and the third is performed using environmental correlation. Combinations of approaches are also possible.

The first method relies on the assumption that the soil moisture content of the sampled sites applies to the complete mapping unit of which the sampled site is part. This method is simple and is always used to describe the general characteristics of soil moisture in the beginning stage of a project.

While powerful geostatistical techniques exist for optimum interpolation of soil moisture from sample grids (Yates and Warrick, 1987; Stein et al., 1988; Western et al., 1998; Wang et al., 2001b), they are appropriate when areas are intensively sampled and there are few, if any, major discontinuities (Webster, 1985). However, the large spatial and temporal variation in soil moisture content and, therefore, the expensive and inefficient survey are preventing the adoption of interpolation and surface fitting methods. There is a need to develop methods for estimating soil moisture content which make the best possible use of all ancillary information, particularly that which is relatively cheap to obtain (Moore et al., 1993; Lark, 1999; Qiu et al., 2000).

The environmental correlation analysis method, however, relates soil moisture content to its environmental factors with a physical basis, and once established, the equations may not be limited to the space and the time for which they were developed only. Recent studies using linear models, particularly multi-linear regression models, have revealed the validity of estimating a soil property from surrogates or easy-to-measure morphological properties (McKenzie and MacLeod, 1989; McKenzie et al., 1991; Manrique et al., 1991; Brubaker et al., 1994; Odeh et al., 1994; McKenzie and Ryan, 1999). For instance, Moore et al. (1993) and Hontoria et al. (1999) have used the stepwise regression method including a combination of forward stepwise and backward elimination procedures in estimating soil attributes with terrain analysis, and in examining the relationship between soil organic carbon and site characteristics, respectively.

However, these more readily observed environmental properties can be complex and the data types are diverse. The classical approach of the "dummy" variables was used for qualitative variables (Hontoria et al., 1999; McKenzie and MacLeod, 1989; Manrique et al., 1991; McKenzie et al., 1991; Moore et al., 1993; Qiu et al., 2001b).

Qiu et al. (2001a,b) explored the profile characteristics and the temporal dynamics of soil moisture content variation and the ability of environmental attributes to predict the 
variability at the Da Nangou catchment in the loess area of China. It was indicated that environmental attributes such as land use and topography play controlling roles in the spatial distribution of soil moisture content (Fu et al., 2003). The spatial variability of soil moisture across landscape varies with both soil depths and temporal evolution.

The purpose of this paper is to identify the most effective method for prediction of soil moisture in space and time using simple environmental attributes. Specific objectives of this paper are (a) to develop multiple-linear regression models for the prediction of soil moisture content using three sets of environmental factors, (b) to compare the goodness of fit of the regression equations, and (c) to compare the performance of the regression equations in predicting soil moisture content on individual dates.

\section{Study area}

\subsection{Description of study area}

The Danangou catchment $\left(36^{\circ} 53^{\prime} \mathrm{N}, 109^{\circ} 17^{\prime} \mathrm{E}\right)$ is situated on the middle part of the Loess Plateau in the northern Shaanxi province in China. The catchment has an area of $3.5 \mathrm{~km}^{2}$, an average slope of $28^{\circ}$ and altitudes between 1075 and $1375 \mathrm{~m}$. There is a significant topographic variability with typical loess hills and gulled surface shapes within the study area. Due to long-term human activity, natural vegetation has been destroyed. Land use types are cropland, fallow land, wasteland, shrub land, orchard,

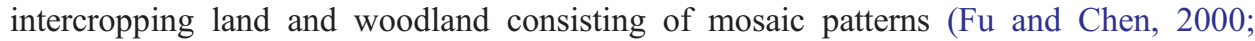
Wang et al., 2001a). Crops are mainly potatoes (Solanum tuberosum), beans (Phaseolus valgaris), maize (Zea mays L.) and millet (Panicum miliaceum) (Wu et al., 2003). Locust trees (Robinia pseudoacacia L.)dominate the woodlands. Annuals such as sweet wormwood (Artemisia annua L.), annual fleabane (Erigeron annuus Pers.) and sandy needle grass (Stipa glareosa p. Smirn) mainly cover most of the grassland. Littleleaf peashrub (Caragana microphylla) in shrub land and apple tree (Malus pumila mill) in orchard are present. Fallow land slowly came into being after cultivated plots were abandoned 2 or 3 years ago. The contour cultivation on cropland is performed from the end of April to beginning of October, and the plough depth is less than $50 \mathrm{~cm}$.

The region has a semiarid continental climate with an average annual temperature of $8.8^{\circ} \mathrm{C}$. Monthly mean temperature ranges from $22.5^{\circ} \mathrm{C}$ in July to $-7{ }^{\circ} \mathrm{C}$ in January. The average annual precipitation is $562 \mathrm{~mm}$ with great interannual variability and $60 \%$ of the rainfall falls between July and September.

The soils, developing on wind-accumulated loess parent material, are thick at an average of 50-80 m. There is no distinct B-horizon in the soil profile. The most common soil in the catchment is loessial soil, and the other two soil types including alluvial soil and calcium skeleton soil are distributed along the first-order channel of the catchment. The detailed description on soil properties is discussed elsewhere in this issue (Hessel et al., 2003; Liu et al., 2003; Messing et al., 2003; Stolte et al., 2003; Wang et al., 2003). The soil characteristic for each soil type is shown in Table 1. It is weakly resistant to erosion $(\mathrm{Fu}, 1989)$. The erosion rate is extreme serious at about $100-120 \mathrm{Mg} \mathrm{ha}^{-2}$ year $^{-1}$ estimated from the catchment measurement during 20 years (Song et al., 1989). 
Table 1

Summary of soil characteristics for each soil type

\begin{tabular}{|c|c|c|c|c|c|c|c|c|c|c|}
\hline Soil type & $\begin{array}{l}\text { Area } \\
\text { (ha) }\end{array}$ & $\begin{array}{l}\text { Area } \\
(\%)\end{array}$ & $\begin{array}{l}\text { Sand } \\
(2-0.05 \\
\mathrm{mm}, \%)\end{array}$ & $\begin{array}{l}\text { Silt } \\
(0.05-0.002 \\
\mathrm{mm}, \%)\end{array}$ & $\begin{array}{l}\text { Clay } \\
(<0.002 \\
\mathrm{mm}, \%)\end{array}$ & $\mathrm{pH}$ & $\begin{array}{l}\text { Total } \\
\text { nitrogen } \\
(\%)\end{array}$ & $\begin{array}{l}\text { Hydrologic } \mathrm{N} \\
(\mathrm{mg} / 100 \mathrm{~g})\end{array}$ & $\begin{array}{l}\text { Total } \\
\text { phosphorus } \\
(\%)\end{array}$ & $\begin{array}{l}\text { Organic } \\
\text { matter }(\%)\end{array}$ \\
\hline Curing loessial soil & 0.98 & 0.28 & 13.95 & 68.25 & 17.80 & 8.80 & 0.03 & 1.83 & 0.06 & 0.48 \\
\hline Typical loessial soil & 69.07 & 19.62 & 11.85 & 71.00 & 17.15 & 8.77 & 0.06 & 4.42 & 0.06 & 1.08 \\
\hline Light loessial soil & 138.9 & 39.46 & 16.08 & 65.87 & 18.05 & 8.83 & 0.03 & 2.13 & 0.06 & 0.48 \\
\hline Eroded loessial soil & 113.9 & 32.36 & 15.13 & 66.20 & 18.67 & 8.84 & 0.05 & 3.28 & 0.05 & 0.78 \\
\hline Red loessial soil & 14.53 & 4.13 & 10.73 & 69.23 & 20.03 & 8.99 & 0.04 & 2.96 & 0.06 & 0.65 \\
\hline Alluvial soil & 1 & 0.28 & 19.20 & 59.70 & 21.10 & 8.78 & 0.04 & 2.74 & 0.06 & 0.68 \\
\hline Calcium skeleton soil & 13.62 & 3.87 & - & - & - & - & - & - & - & - \\
\hline Total & 352 & 100 & 14.41 & 67.04 & 18.55 & 8.84 & 0.04 & 2.75 & 0.06 & 0.65 \\
\hline
\end{tabular}

(-) Not measured. 


\section{Methods}

\subsection{Sampling methods}

In 1998, 26 sample sites were selected for measuring soil moisture content and spatial factors (Fig. 1). These sites were distributed throughout the catchment according to different topographic positions and land uses (Qiu et al., 2000, 2001a).

In 1999, four adjacent hillslopes (67 sites) were selected because of logistic advantages (Qiu and Zhang, 1999; Qiu et al., 2001b), particularly in relation to survey time (Fig. 2). Most of the 67 sites in the four neighboring hillslopes are located in two adjacent sub-catchments (Fig. 2). Another group of sample sites (14 sites) is spread throughout the catchment to ensure representation of the whole catchment (Fig. 2). As a consequence, the total number of sites that were sampled in 1999 was 81 (Fig. 2).

\subsection{Survey methods}

\subsubsection{Soil moisture content measurement}

Volumetric soil moisture content was measured using a calibrated Delta-T theta probe (Eijkelkamp Agrisearch Equipment, Netherlands) based on time domain reflec-

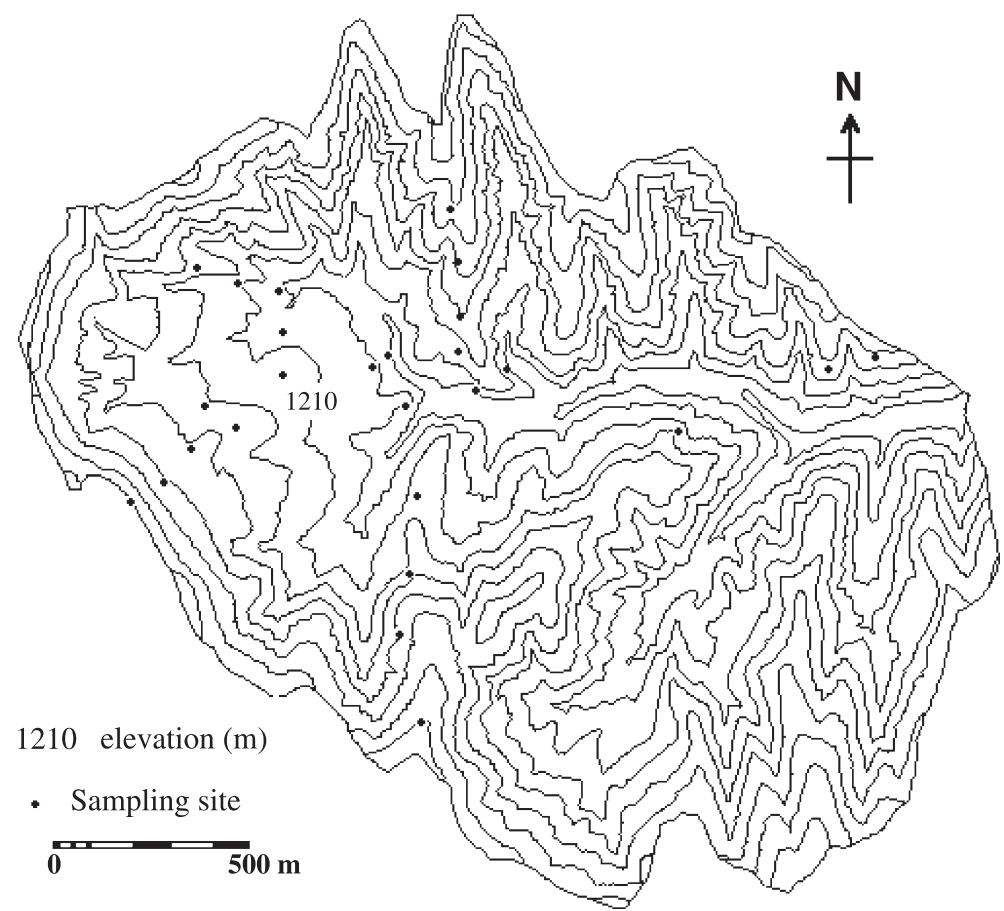

Fig. 1. Spatial distribution of sampling sites in 1998 in the Danangou catchment. Contour interval: $25 \mathrm{~m}$. 

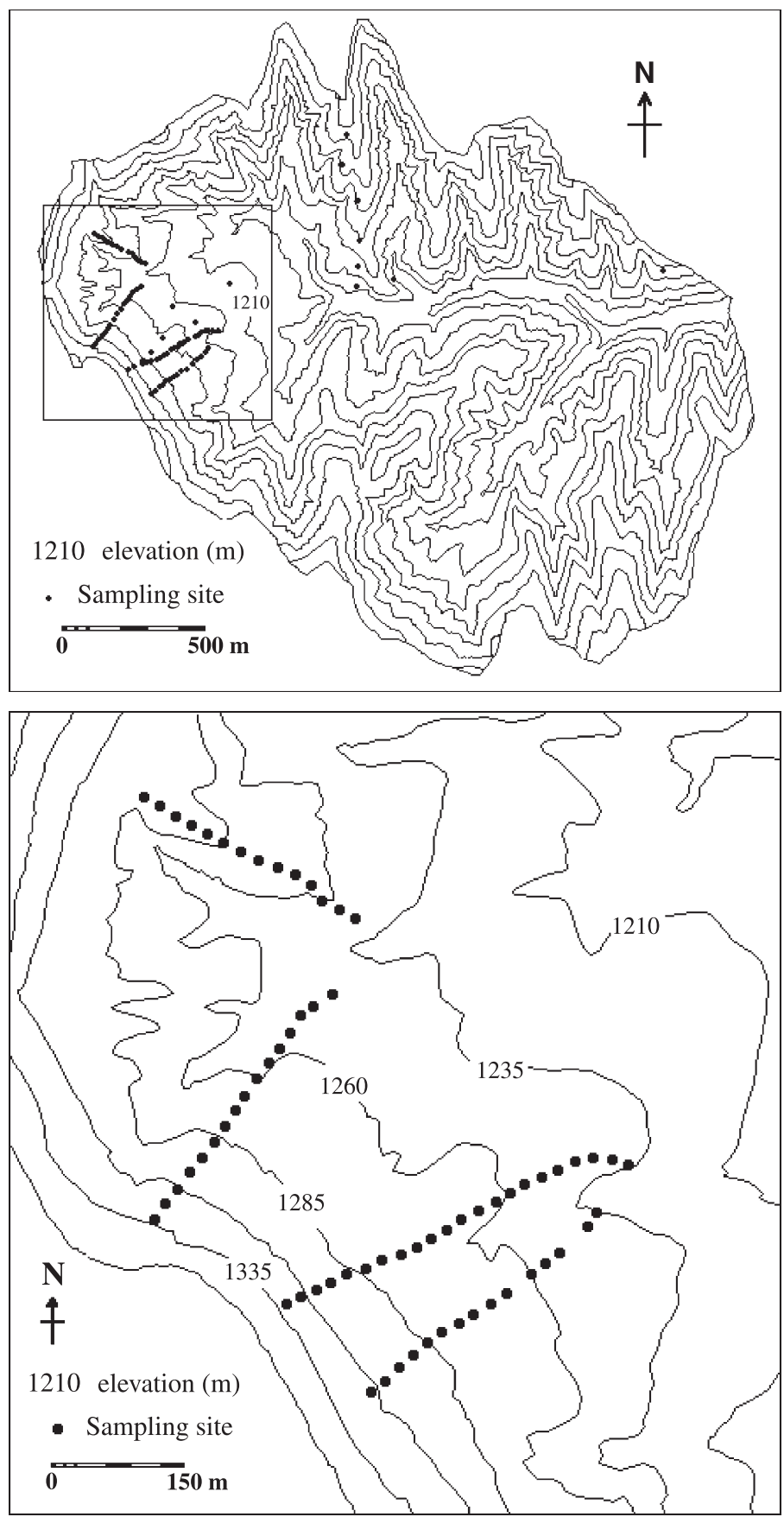

Fig. 2. Spatial distribution of sampling sites in 1999 in the Da Nangou catchment with the contour interval of $25 \mathrm{~m}$. 
tometry (TDR) at approximately biweekly intervals during the period May to October 1998 and May to September 1999, providing a spectrum of moisture conditions ranging from dry to wet (Qiu et al., 2000, 2001a,b). At each sample site, five sampling points were taken to measure soil moisture content at five depths: $0-5,10-$ $15,20-25,40-45$ and $70-75 \mathrm{~cm}$. The mean soil moisture content for the five sampling points was computed as the soil moisture content at each depth on the sample site.

\subsubsection{Environmental attributes survey}

Each sampling site was surveyed, and the land use types and the spatial characteristics were recorded. The spatial attributes are as follows: profile slope shape, plan slope shape, aspect, slope gradient and elevation.

The daily meteorological attributes that were used are as follows: total precipitation, mean air temperature, mean relative humidity, mean ground temperature, mean wind velocity and mean soil temperature at depths of 5, 10, 15, 20, 40, 60 and $100 \mathrm{~cm}$. Most of the meteorological data were obtained from an automatic meteorological station $3 \mathrm{~km}$ from the Danangou catchment. There is little difference in elevation and meteorological characteristics between the meteorological station and the Da Nangou catchment. Only precipitation was recorded by five tipping bucket rain gauges located in the catchment itself.

\subsection{Prediction model development}

Three basic multiple-linear regressions were performed using SPSS software (SPSS for windows 8.0.0, SPSS) to develop the prediction models of soil moisture content from three different sets of variables. The first is the land use-based generalized multiple-linear regression model (landuse-GM model) that relates one dependent variable of soil moisture to independent land use types. The second is the spatial data-based generalized regression model (spatial-GM model) to which relates land use and topographic variables. The third is the spatiotemporal data-based stepwise multiple-linear regression model (spatiotemporal-SM model), with the spatial and temporal data including both the spatial and meteorological variables. The stepwise method is a combination of forward enter and backward elimination procedures. The probability for entry was $P_{\text {in }}=0.01$ and the probability for removal was $P_{\text {out }}=0.05$.

\subsubsection{Dependent variables}

The soil moisture content measurements during the rainfall season from the end of June to the beginning of September were selected as the dependent data for the development of regression equations, since most of the storm/runoff events were found in this period (data from Ansai County Meteorological Station). A total of 11 measurements was selected: 21 June 1998, 2 July 1998, 4 August 1998, 19 August 1998, 2 September 1998, 23 June 1999, 12 July 1999, 18 July 1999, 2 August 1999, 10 August 1999, and 9 September 1999. There are 26 sites for each measurement in 1998 and 81 sites for each in 1999. Therefore, the sample size for the regression is 
616. The remaining three measurements in 1999 (i.e. 13 May 1999, 23 May 1999 and 10 June 1999) were used as the validation data.

\subsubsection{Independent variables}

There are seven types of land use identified in the field: shrub land, woodland, orchard, intercropping land, wasteland, fallow land, and cropland. The land use was transformed into seven "dummy" variables ( 0 for absence and 1 for presence) that can be used as the independent variables (Table 2).

Both the profile slope shape and the plan slope shape were classified into three types: convex slope, straight slope and concave slope, and were also transformed into the "dummy" variable. Aspect (clockwise from north), which is a circular variable, was transformed into sin(aspect) and cos(aspect), as recommended by Bourennane et al. (1996) and King et al. (1999). Down elevation was defined as the elevation deviation from the outlet $(1085 \mathrm{~m})$. Slope gradient was recorded as a unit of degree. As a consequence, a total of 10 topographic variables will be used as the explanatory variables (Table 3).

Each daily meteorological attribute was transformed into 10 variables representing the average values for the recent 1-10 days, respectively, except the precipitation, which was transformed into 10 variables representing the total values for the recent $1-10$ days. As a result, 120 meteorological variables were used.

\subsection{Assessment of model performance}

No prediction model can ever be expected to outperform all other models on all reasonable data sets examined. Thus we insist that models satisfy several assessment

Table 2

Coefficients of generalized multiple-linear regression models with land use attributes (landuse-GM model) developed for the prediction of soil moisture content at different depths

\begin{tabular}{lccccc}
\hline Independent variables & \multicolumn{4}{l}{ Dependent variable } \\
\cline { 2 - 6 } & \multicolumn{4}{l}{ Soil moisture content $(\%)$} \\
\cline { 2 - 6 } & $0-5 \mathrm{~cm}$ & $10-15 \mathrm{~cm}$ & $20-25 \mathrm{~cm}$ & $40-45 \mathrm{~cm}$ & $70-75 \mathrm{~cm}$ \\
\hline Intercept & $8.8372^{* *}$ & $10.4146^{* *}$ & $11.3010^{* *}$ & $11.8031^{* *}$ & $11.7400^{* *}$ \\
Shrub land $^{\mathrm{a}}$ & -1.9840 & $-3.3412^{* *}$ & $-4.6083^{* *}$ & $-6.3390^{* *}$ & $-6.8202^{* *}$ \\
Woodland $^{\mathrm{a}}$ & $2.8661^{* *}$ & 1.2336 & 0.2427 & -0.4801 & -0.0278 \\
Orchard $^{\mathrm{a}}$ & 1.5162 & 0.6054 & -0.0254 & -0.7250 & -0.2289 \\
Intercropping land $^{\mathrm{a}, \mathrm{b}}$ & $0^{\mathrm{b}}$ & 0 & 0 & 0 & 0 \\
Wasteland $^{\mathrm{a}}$ & -0.2972 & -0.3092 & -1.2346 & -0.6804 & -0.2836 \\
Fallow land $^{\mathrm{a}}$ & -0.8739 & -0.3836 & -0.1279 & 0.6540 & $1.8673^{* *}$ \\
Cropland $^{\mathrm{a}}$ & -0.5547 & -0.1639 & -0.0589 & 0.5559 & $1.7718^{* *}$ \\
$F$ & $3.48^{* *}$ & $3.76^{* *}$ & $8.84 * *$ & $28.27 * *$ & $44.17^{* *}$ \\
\hline
\end{tabular}

${ }^{a}$ Binary response ( 0 for absence and 1 for presence).

b This independent variable was deleted and designated as zero.

** Significant ( $p=99 \%$ ) based on the $t$-test. 
Table 3

Coefficients of generalized multiple-linear regression models with spatial attributes (spatial-GM model) developed for the prediction of soil moisture content at different depths

\begin{tabular}{|c|c|c|c|c|c|}
\hline \multirow[t]{3}{*}{ Independent variables } & \multicolumn{5}{|c|}{ Dependent variable } \\
\hline & \multicolumn{5}{|c|}{ Soil moisture content (\%) } \\
\hline & $0-5 \mathrm{~cm}$ & $10-15 \mathrm{~cm}$ & $20-25 \mathrm{~cm}$ & $40-45 \mathrm{~cm}$ & $70-75 \mathrm{~cm}$ \\
\hline Intercept & $11.7529 * *$ & $14.0746^{* *}$ & $15.4774 * *$ & $15.9356^{* *}$ & $16.2580 * *$ \\
\hline Shrub land ${ }^{\mathrm{a}}$ & -0.8810 & -1.8902 & $-2.7906^{* *}$ & $-4.4734^{* *}$ & $-4.8992 * *$ \\
\hline Woodland $^{\mathrm{a}}$ & $2.6563^{*}$ & 0.7740 & -0.2347 & -0.9262 & -0.4632 \\
\hline Orchard $^{\mathrm{a}}$ & 1.0221 & -0.2395 & -0.9454 & $-1.6208^{*}$ & -1.2247 \\
\hline Intercropping land $\mathrm{d}^{\mathrm{a}, \mathrm{b}}$ & 0 & 0 & 0 & 0 & 0 \\
\hline Wasteland $^{\mathrm{a}}$ & -0.0600 & -0.5365 & -1.5019 & -0.9412 & -0.5466 \\
\hline Fallow land ${ }^{\mathrm{a}}$ & -0.4887 & 0.1445 & 0.4414 & $1.2436^{*}$ & $2.4552 * *$ \\
\hline Cropland $^{\mathrm{a}}$ & -0.4545 & -0.0171 & 0.1895 & 0.8611 & $2.0470 * *$ \\
\hline Profile convex slope ${ }^{a}$ & -0.9230 & -0.8489 & -0.5784 & -0.5447 & -0.6761 \\
\hline Profile straight slope $^{\mathrm{a}}$ & -0.4196 & -0.5888 & -0.4250 & -0.3195 & -0.4411 \\
\hline Profile concave slope $\mathrm{e}^{\mathrm{a}, \mathrm{b}}$ & 0 & 0 & 0 & 0 & 0 \\
\hline Plan convex slope $\mathrm{a}^{\mathrm{a}}$ & 0.4368 & 0.2668 & 0.3186 & 0.2508 & 0.3408 \\
\hline Plan straight slope ${ }^{\mathrm{a}, \mathrm{b}}$ & 0 & 0 & 0 & 0 & 0 \\
\hline Plan concave slope $^{\mathrm{a}}$ & -0.0107 & 0.4696 & 0.2015 & -0.0827 & -0.4806 \\
\hline $\operatorname{Sin}($ aspect) & -0.0756 & -0.3049 & -0.4608 & $-0.4968^{*}$ & -0.4073 \\
\hline Cos(aspect) & 0.2579 & 0.1969 & 0.1260 & 0.1944 & 0.1619 \\
\hline Slope gradient $\left({ }^{\circ}\right)$ & -0.0452 & -0.0355 & -0.0446 & $-0.0465^{*}$ & $-0.0503 * *$ \\
\hline Down elevation $(\mathrm{m})$ & -0.0125 & $-0.0163 * *$ & $-0.0194 * *$ & $-0.0195^{* *}$ & $-0.0210^{* *}$ \\
\hline$F$ & $1.94 * *$ & $2.58 * *$ & $5.83 * *$ & $15.68 * *$ & $23.26 * *$ \\
\hline
\end{tabular}

criteria before they are accepted as satisfactory (Laslett et al., 1987; Legates and McCabe, 1999).

\subsubsection{Summary statistics}

The comparison of the mean, the standard deviation (S.D.), the minimum (Min) and the maximum (Max) between the predicted and observed soil moisture contents can provide the basic supporting information for the assessment of model performance.

\subsubsection{Correlation-based indices}

The coefficient of determination $\left(R^{2}\right)$ and the adjusted coefficient of determination $\left(R_{\mathrm{a}}^{2}\right)$ can describe the proportion of the total variance in the observed data that can be explained by the model. Both indices indicate the degree to which the models explain variation in soil moisture content. They should be close to 1 for the best prediction methods. However, they are insensitive to additive and proportional differences between the model predictions and observations. Large values can be obtained even when the model-predicted values differ considerably in magnitude and variability. So, they cannot measure the precision of models. 


\subsubsection{Mean absolute error (MAE)}

This measure, a nonnegative statistic that has no upper bound, describes the difference between the model predictions and observations in the units of the variable (Willmott, 1981), and is given by

$$
\mathrm{MAE}=N^{-1} \sum_{i=1}^{N}\left|O_{i}-P_{i}\right|
$$

where $O_{i}$ and $P_{i}$ are the observed and predicted soil moisture of sample $i$, respectively, and $N$ is the sample size.

The MAE measures the bias or precision of prediction and it should be as small as possible for unbiased and precise prediction models.

\subsubsection{Akaike information criterion (AIC)}

The comparison of the explained variation and the precision of models is not enough for selecting satisfactory models, since increasing the number of independent variable almost always improves the fit of the regression (Lark, 1999). In addition, increasing the number of independent variable requires an increasing cost in survey and analysis (Odeh et al., 1994). An appropriate statistic for comparing regressions of the same observations of soil moisture content on different sets of independent variables is the Akaike information criterion (AIC) (Webster and McBratney, 1989), since this criterion can provide a satisfactory compromise between goodness of fit and parsimony.

The AIC is estimated by

$$
\mathrm{AIC}=N \operatorname{lnSSE}+2 \mathrm{Nv}
$$

where SSE is the sum of square of error, and is given by

$$
\mathrm{SSE}=\sum_{i=1}^{N}\left(O_{i}-P_{i}\right)^{2}
$$

where Nv is the number of independent variables, $O_{i}$ and $P_{i}$ are the observed and predicted soil moisture of sample $i$, respectively, and $N$ is the sample size.

When comparing two models with different numbers of predictors, the models with the best performance is the one for that AIC is least.

\section{Results and discussion}

\subsection{Overview of prediction models of soil moisture content}

The intercept constants and the regression coefficients of the independent variables for the prediction models of soil moisture at five soil depths are shown in Tables 2-4. The $F$-value for each regression and the $t$-test result for each coefficient are also given in Tables 2-4. 


\subsubsection{Land use-based generalized multiple-linear regression models (landuse-GM model)}

It is noted here that one sub-variable of each categorical attribute is deleted during regression and in turn its regression coefficient is designated as zero such as intercropping land (Table 2). The positive or negative sign of the regression coefficients of variables reflects its relationship with soil moisture (Qiu et al., 2001a,b). For example, all the coefficients for shrub land are negative since soil is generally drier with this land use respect to other types of land use due to the strong evaporation from the sparsely covered ground surface and the strong water uptake through deep roots. Cropland with its sparse coverage and shallow roots is quite dry in shallower soil horizons owing to the strong evaporation from the soil surface. One the contrary, it is more wet in deeper soil horizons as a result of little transpiration (Qiu et al., 2001a,b).

\subsubsection{Spatial data-based generalized multiple-linear regression models (spatial-GM model)}

As in the case of the landuse-GM model, one variable of each categorical attribute is deleted during regression and, in turn, its regression coefficients are designated as zero; examples are intercropping land, profile concave slope and plan straight slope. It is obvious that the regression displays an interesting relationship between soil moisture and terrain indices (Table 3). For example, soil moisture shows a negative relation with slope gradient and down elevation (Qiu et al., 2000, 2001a,b). Slope angle influences infiltration, drainage and runoff, and steeper slopes are likely to be drier than flat areas owing to lower infiltration rates, rapid subsurface drainage and higher surface runoff (Nyberg, 1996). The greater relative elevation can foster more soil water draining down and will receive less water upslope (Robinson and Dean, 1993).

\subsubsection{Spatiotemporal data-based stepwise multiple-linear regression models (spatiotem- poral-SM model)}

Table 4 shows clearly that the antecedent precipitation has a significant influence on the soil moisture distribution in time (Qiu et al., 2001b). The soil moisture content in shallower soil layers seems mainly influenced by the total precipitation of more recent days while soil moisture at deeper depths appears to be related to that of earlier days. In addition, the soil moisture content is also influenced by the air temperature, relative humidity, ground temperature, wind velocity and soil temperature since these meteorological variables are associated with soil moisture loss through evapotranspiration.

Both the relationships between soil moisture and environmental attributes and the reciprocal relations among environmental attributes have considerable influences on the stepwise regression. For example, the variables of slope gradient and down elevation were selected by all regression equations because of their own significant influencing on the soil moisture distribution (Qiu et al., 2001a,b). On the other hand, the variables of soil temperature at 10,20 and $40 \mathrm{~cm}$ were not entered into any regression models because they are associated very strongly with the soil temperature at other depths.

In other words, all three regression models were developed based on the physical relationship between soil moisture and environmental attributes since they incorporate the significant environmental factors that have important influence on soil moisture distribution. 
Table 4

Coefficients of stepwise multiple-linear regression models with spatiotemporal attributes (spatiotemporal-SM model) developed for the prediction of soil moisture content at different depths

\begin{tabular}{|c|c|c|c|c|c|}
\hline \multirow[t]{3}{*}{ Independent variables } & \multicolumn{5}{|c|}{ Dependent variable } \\
\hline & \multicolumn{5}{|c|}{ Soil moisture content $(\%)$} \\
\hline & $0-5 \mathrm{~cm}$ & $10-15 \mathrm{~cm}$ & $20-25 \mathrm{~cm}$ & $40-45 \mathrm{~cm}$ & $70-75 \mathrm{~cm}$ \\
\hline Intercept & $-5.4983^{*}$ & $-6.9123^{*}$ & $23.8388 * *$ & $4.9430^{*}$ & $8.9261 * *$ \\
\hline Shrub land ${ }^{\mathrm{a}}$ & - & $-1.6591 * *$ & $-2.8005^{* *}$ & $-5.1053 * *$ & $-3.9322 * *$ \\
\hline Woodland $^{\mathrm{a}}$ & $3.0369 * *$ & $0.8667 *$ & - & $-1.6018 * *$ & - \\
\hline Orchard $^{\mathrm{a}}$ & $1.2612 *$ & - & $-1.8027 * *$ & $-2.6824 * *$ & - \\
\hline Intercropping land $^{\mathrm{a}}$ & - & - & - & - & $1.2821^{*}$ \\
\hline Wasteland $^{\mathrm{a}}$ & - & - & $-1.0512 *$ & $-2.0634 * *$ & - \\
\hline Fallow land ${ }^{\mathrm{a}}$ & - & - & - & - & $2.5035^{* *}$ \\
\hline Cropland $^{\mathrm{a}}$ & - & - & - & - & $2.8531 * *$ \\
\hline Profile concave slope $^{\mathrm{a}}$ & - & $0.6038^{*}$ & - & - & - \\
\hline $\operatorname{Sin}($ aspect) & - & $-0.3551^{*}$ & $-0.4517 * *$ & - & - \\
\hline Slope gradient $\left({ }^{\circ}\right)$ & $-0.0469 * *$ & $-0.0372 * *$ & $-0.0434^{* *}$ & $-0.0410^{* *}$ & $-0.0508^{* *}$ \\
\hline Down elevation (m) & $-0.0132 * *$ & $-0.0156^{* *}$ & $-0.0193 * *$ & $-0.0194 * *$ & $-0.0177 * *$ \\
\hline $\begin{array}{l}\text { Total precipitation of } \\
\text { recent } 4 \text { days }(\mathrm{mm})\end{array}$ & $0.2562 * *$ & - & - & - & - \\
\hline $\begin{array}{l}\text { Total precipitation of } \\
\text { recent } 7 \text { days }(\mathrm{mm})\end{array}$ & $0.3418^{* *}$ & $0.2264 * *$ & - & - & - \\
\hline $\begin{array}{l}\text { Total precipitation of } \\
\text { recent } 9 \text { days }(\mathrm{mm})\end{array}$ & - & $0.1029 * *$ & - & $0.0372 *$ & - \\
\hline $\begin{array}{l}\text { Total precipitation of } \\
\text { recent } 10 \text { days }(\mathrm{mm})\end{array}$ & - & - & - & $0.0735^{* *}$ & - \\
\hline $\begin{array}{l}\text { Mean daily air temperature } \\
\text { of recent } 2 \text { days }\left({ }^{\circ} \mathrm{C}\right)\end{array}$ & - & $-1.7095^{* *}$ & - & - & - \\
\hline $\begin{array}{l}\text { Mean daily air temperature } \\
\text { of recent } 3 \text { days }\left({ }^{\circ} \mathrm{C}\right)\end{array}$ & $-1.6594 * *$ & - & $-0.9810^{* *}$ & - & $0.4503 *$ \\
\hline $\begin{array}{l}\text { Mean daily relative humidity } \\
\text { of recent } 1 \text { day }(\%)\end{array}$ & - & $-0.1436^{* *}$ & - & - & - \\
\hline $\begin{array}{l}\text { Mean daily relative humidity } \\
\text { of recent } 6 \text { days }(\%)\end{array}$ & - & - & - & $-0.3099 * *$ & - \\
\hline $\begin{array}{l}\text { Mean daily relative humidity } \\
\text { of recent } 9 \text { days }(\%)\end{array}$ & $0.0856^{* *}$ & $0.2548^{* *}$ & - & - & - \\
\hline $\begin{array}{l}\text { Mean daily relative humidity } \\
\text { of recent } 10 \text { days }(\%)\end{array}$ & - & - & $0.2424 * *$ & $0.3715^{* *}$ & - \\
\hline $\begin{array}{l}\text { Mean daily ground temperature } \\
\text { of recent } 2 \text { days }\left({ }^{\circ} \mathrm{C}\right)\end{array}$ & - & - & - & - & $-0.5702 * *$ \\
\hline $\begin{array}{l}\text { Mean daily ground temperature } \\
\text { of recent } 4 \text { days }\left({ }^{\circ} \mathrm{C}\right)\end{array}$ & - & $0.8474 * *$ & - & - & - \\
\hline $\begin{array}{l}\text { Mean daily ground temperature } \\
\text { of recent } 5 \text { days }\left({ }^{\circ} \mathrm{C}\right)\end{array}$ & - & - & $-1.9567 * *$ & - & - \\
\hline $\begin{array}{l}\text { Mean daily wind velocity } \\
\text { of recent } 4 \text { days }(\mathrm{m} / \mathrm{s})\end{array}$ & - & - & - & $-1.7517^{* *}$ & - \\
\hline $\begin{array}{l}\text { Mean daily soil }(-5 \mathrm{~cm}) \text { temperature } \\
\text { of recent } 1 \text { day }\left({ }^{\circ} \mathrm{C}\right)\end{array}$ & $0.6171 * *$ & $1.0133 * *$ & - & $0.3427 * *$ & $0.5525^{* *}$ \\
\hline $\begin{array}{l}\text { Mean daily soil }(-5 \mathrm{~cm}) \text { temperature } \\
\text { of recent } 2 \text { days }\left({ }^{\circ} \mathrm{C}\right)\end{array}$ & $1.1473 * *$ & - & - & - & - \\
\hline $\begin{array}{l}\text { Mean daily soil }(-5 \mathrm{~cm}) \text { temperature } \\
\text { of recent } 4 \text { days }\left({ }^{\circ} \mathrm{C}\right)\end{array}$ & - & - & $2.6209^{* *}$ & - & - \\
\hline
\end{tabular}


Table 4 (continued)

\begin{tabular}{|c|c|c|c|c|c|}
\hline \multirow[t]{3}{*}{ Independent variables } & \multicolumn{5}{|c|}{ Dependent variable } \\
\hline & \multicolumn{5}{|c|}{ Soil moisture content $(\%)$} \\
\hline & $0-5 \mathrm{~cm}$ & $10-15 \mathrm{~cm}$ & $20-25 \mathrm{~cm}$ & $40-45 \mathrm{~cm}$ & $70-75 \mathrm{~cm}$ \\
\hline $\begin{array}{l}\text { Mean daily soil }(-15 \mathrm{~cm}) \text { temperature } \\
\text { of recent } 5 \text { days }\left({ }^{\circ} \mathrm{C}\right)\end{array}$ & - & - & $-0.7515^{* *}$ & - & - \\
\hline $\begin{array}{l}\text { Mean daily soil }(-60 \mathrm{~cm}) \text { temperature } \\
\text { of recent } 10 \text { days }\left({ }^{\circ} \mathrm{C}\right)\end{array}$ & - & - & - & - & $-0.4195^{* *}$ \\
\hline $\begin{array}{l}\text { Mean daily soil }(-100 \mathrm{~cm}) \text { temperature } \\
\text { of recent } 1 \text { day }\left({ }^{\circ} \mathrm{C}\right)\end{array}$ & - & - & - & - & $0.4157 * *$ \\
\hline$F$ & $230.95 * *$ & $166.00 * *$ & $151.69 * *$ & $70.67 * *$ & $41.54 * *$ \\
\hline
\end{tabular}

\subsection{Goodness of fit of prediction models of soil moisture content}

This section will investigate the goodness of fit of the soil moisture prediction models using all the data that have been used in the regression analysis (sample size is 616).

A measure of the goodness of fit of multi-linear regression is the comparison of summary statistics between the predicted and measured soil moisture content values, which have been used in the regression analysis (sample size is 616). This result is shown in Fig. 3. Obviously, there is little difference between the predicted mean by the three methods and the observed mean (Fig. 3a). However, based on the degree to which the predicted standard deviation (S.D.) matches the observed (Fig. 3b) value, the S.D. predicted by spatiotemporal-SM model is closest to the measured value, while those by spatial-GM model and landuse-GM model are further from the observed S.D. Such trend was also found in the goodness of fit of the predicted minimum and maximum values to the observed values as shown in Fig. $3 \mathrm{c}$ and $\mathrm{d}$, respectively.

The coefficient of determination $\left(R^{2}\right)$ describes the proportion of the total variance in the observed data that can be explained by the model, and can measure the degree to which models are optimal. The variation in soil moisture content consists of the spatial variation and temporal variation. It is clear (Fig. 4a) that the landuse-GM model can account for $3.31-30.32 \%$ of the total variation in soil moisture, and the spatial-GM model can explain $4.33-35.15 \%$, which implies only little improvement. This may be partly due to the strong correlation between land use and topography (Qiu et al., 2000, 2001a). However, 43.07$79.24 \%$ of the soil moisture variability can be explained by the spatiotemporal-SM model since this prediction model incorporates both the spatial and temporal attributes that are closely related to the soil moisture variability. Additionally, the $R^{2}$ displays an interesting trend with increasing soil depth, i.e. the $R^{2}$ of the spatiotemporal-SM model decreases while it increases for the other two models. This may be because the meteorological factors (with high-temporal and low-spatial variation) play a more significant influence on the surface soil moisture with high-temporal and low-spatial variation than that of land use and topography (with low-temporal and high-spatial variation). However, the influences of 
(a)

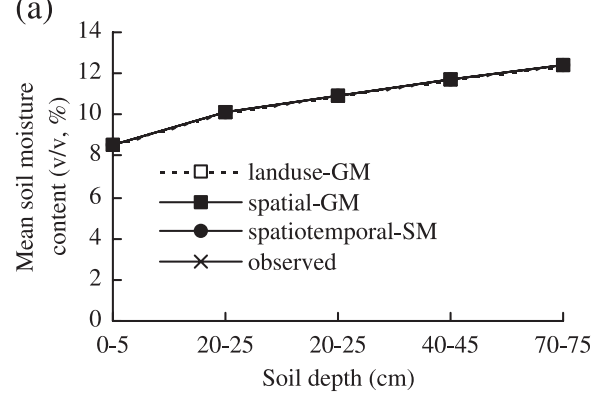

(c)

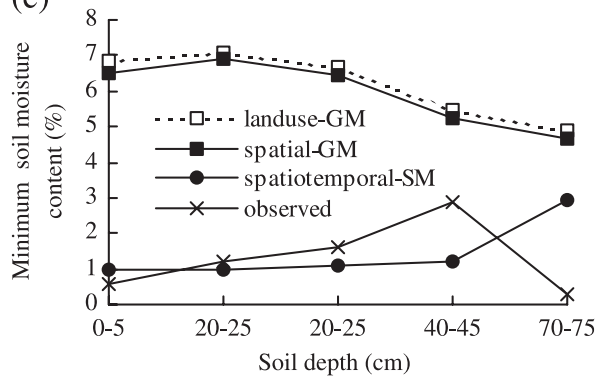

(b)

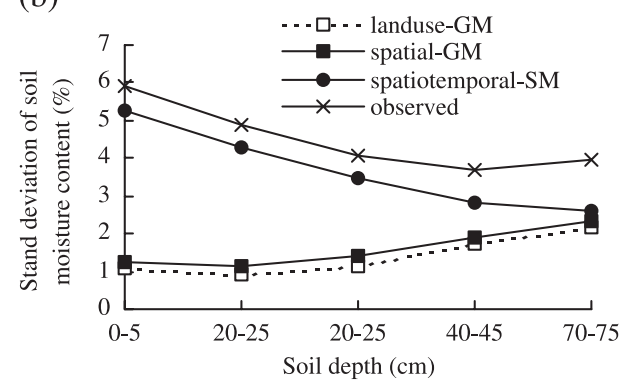

(d)

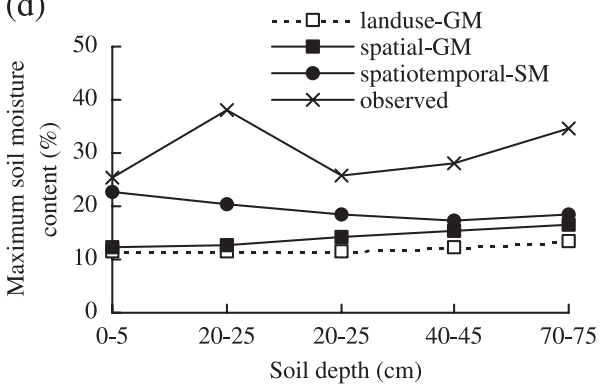

Fig. 3. Observed and predicted statistics of soil moisture content by regression models with sample of 616. (a) Mean; (b) stand deviation; (c) minimum; (d) maximum. Landuse-GM model=generalized multiple-linear regression with land use types; spatial-GM model=generalized multiple-linear regression with spatial factors; spatiotemporal-SM model=stepwise multiple-linear regression with spatial and meteorological factors.

all these environmental factors decrease with increasing of soil depth, and this is especially the case for the meteorological factors. Consequently, the soil moisture at larger depths displays a low-temporal and high-spatial variation mainly owing to the heterogeneity of land use and topography (Qiu et al., 2001b). The adjusted coefficient of determination $R_{\mathrm{a}}^{2}$ shows a similar trend (Fig. 4b).

The mean absolute error (MAE) measures the bias or precision of prediction model, and should be as small as possible for unbiased and precise prediction. Fig. 5 shows that MAE of the spatiotemporal-SM model displays a stable smallest value implying that it is the most unbiased or the most precise in prediction of soil moisture. The spatial-GM model is slightly more precise than the landuse-GM model because of the strong correlation between land use and topography. It is interesting that the MAE of both the spatial-GM model and landuseGM model decreases with increasing soil depth. Additionally, the difference between the spatiotemporal-SM model and the other two models also shows a decreasing trend with increasing soil depth. Consequently, there is little difference among the three models for the prediction of soil moisture at $70-75 \mathrm{~cm}$. This is because the influence of spatial factors on the soil moisture content gets more significant than that of meteorological factors with increasing of soil depth (Qiu et al., 2001b).

A problem in selecting satisfactory models for the prediction of soil moisture content is that the residual sum of squares can always be diminished, and the fit improved by adding 

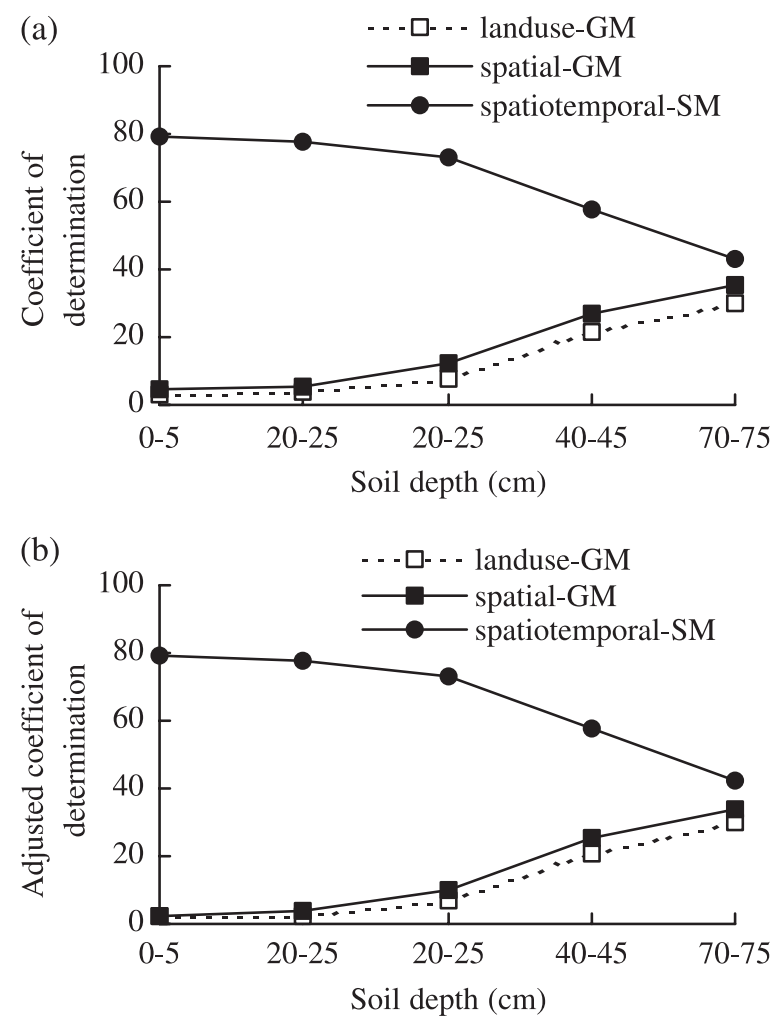

Fig. 4. Correlation-based measures of fitness of regression models for prediction of soil moisture content (sample is 616). (a) Coefficient of determination $R^{2}$; (b) adjusted coefficient of determination $R_{\mathrm{a}}^{2}$.

parameters to the models. On the other hand, this increase in the number of predictors also results in increasing cost in survey and analysis. A satisfactory compromise between goodness of fit and parsimony can be achieved by applying the Akaike information

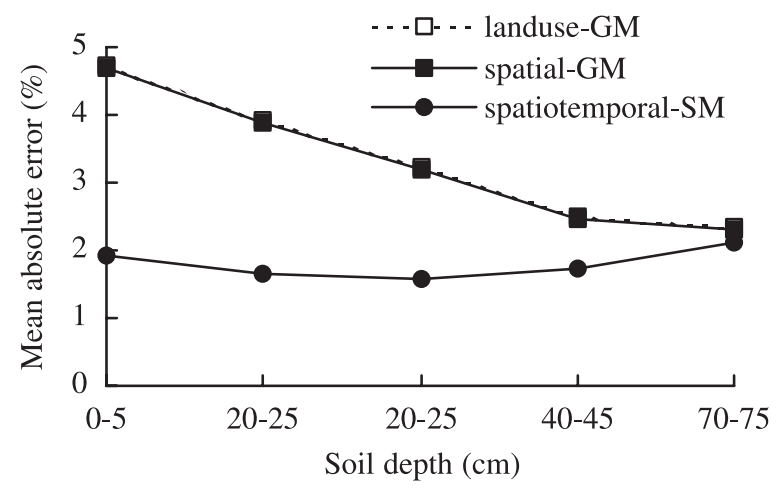

Fig. 5. Mean absolute error of soil moisture content obtained with the prediction models (sample is 616). 
criterion (AIC). The model to choose is the one for which the value of these two criteria is least. Fig. 6 indicates that the value of the AIC exhibits the same trend as that of the MAE. It is obvious that the spatiotemporal-SM model is considerably preferable to the other two prediction models because of the smaller values of the AIC. There is little difference between the landuse-GM model and the spatial-GM model.

\subsection{Performance of models in predicting soil moisture on individual dates}

This section will investigate the performance of the regression models in predicting the soil moisture content on individual occasions. Only the measurements in 1999 used as example were shown in Figs. 7-9, since it is the same results for 1998 and 1999. Note that the observation on 2 May 1999 was not included because of a lack of meteorological data and that the observations during the rainfall period between 23 June 1999 and 9 September 1999 have been used for the development of the regression equations. The models can be validated using the remaining three observations: 13 May 1999, 23 May 1999 and 10 June 1999 that have not been included in regression analysis.

The mean soil moisture content predicted by the landuse-GM model and the spatialGM model shows stable values throughout the measurement periods (Fig. 7) because these models can describe only the spatial distribution rather than the temporal dynamics of soil moisture content. This is because they include only spatial data (see Tables 2 and 3). However, the mean soil moisture content estimated by the spatiotemporal-SM model displays a similar temporal evolution as that of the observed mean values (Fig. 7), since this model incorporates both spatial and meteorological attributes (Table 4). This is an important result because it implies that the spatiotemporal-SM model can describe the temporal trend in the spatial distribution of soil moisture. There is little difference in mean soil moisture content between observed and predicted by the spatiotemporal-SM model during the rainfall period between 23 June 1999 and 9 September 1999, since these data have been used in the regression analysis. While model performance is somewhat lower during the period between 13 May 1999 and 10 June 1999, because these data have not been included in developments of regression models.

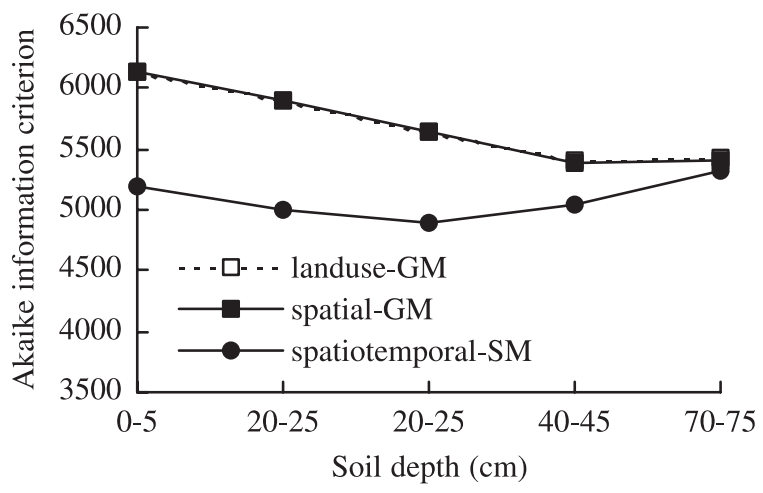

Fig. 6. Akaike information criterion of prediction models of soil moisture content (sample is 616). 

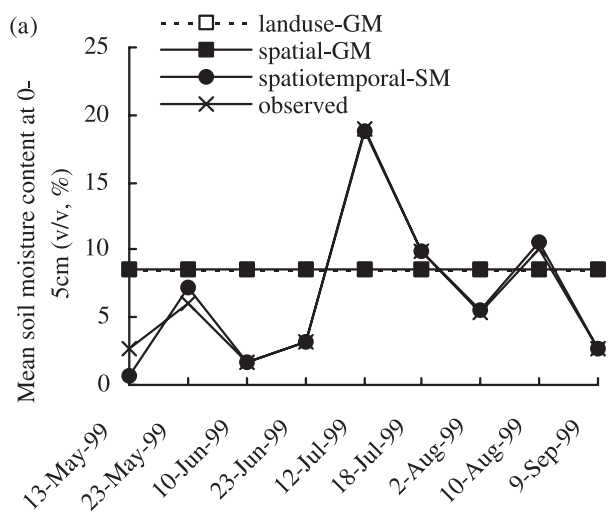

Date (day)
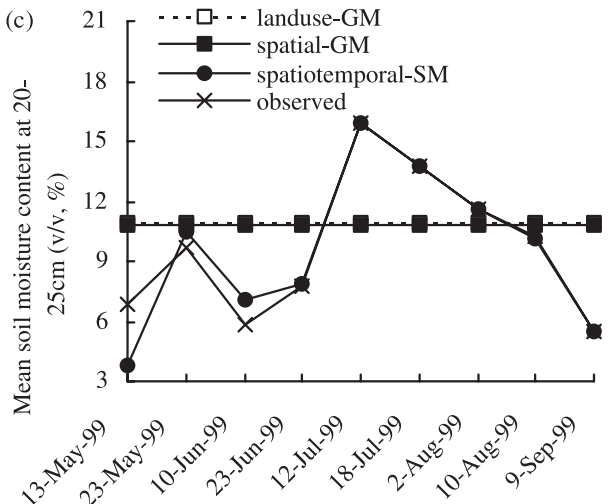

Date (day)

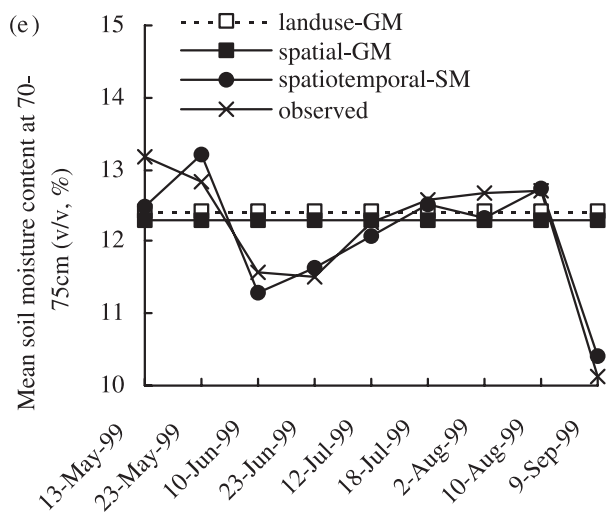

Date (day)

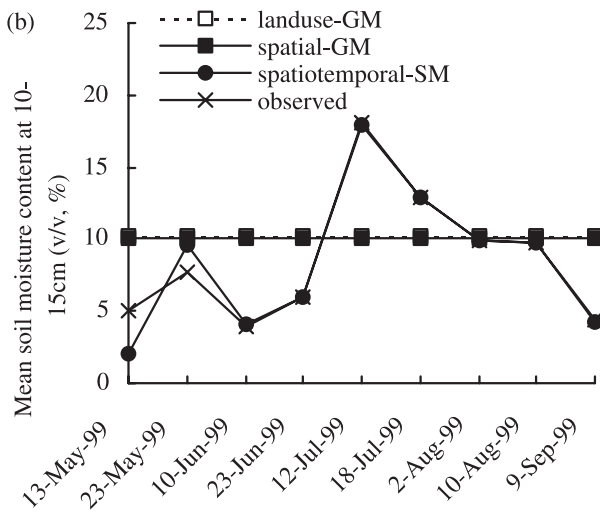

Date (day)

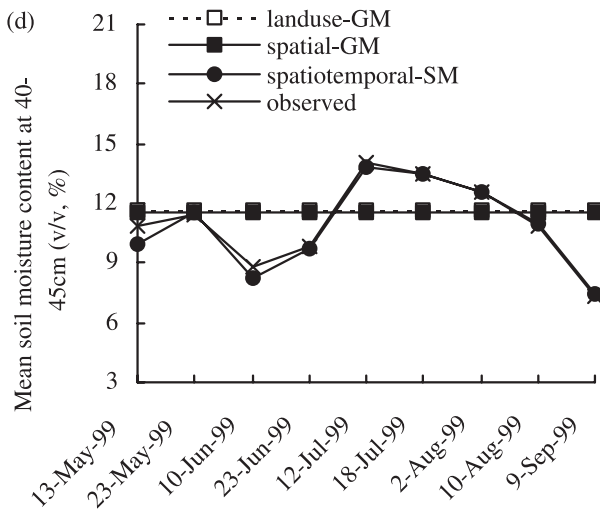

Date (day)

Fig. 7. The observed and predicted mean soil moisture content at five depths in 1999 (sample is 81 ). (a) $0-5 \mathrm{~cm}$; (b) $10-15 \mathrm{~cm}$; (c) $20-25 \mathrm{~cm}$; (d) $40-45 \mathrm{~cm}$; (e) $70-75 \mathrm{~cm}$. 

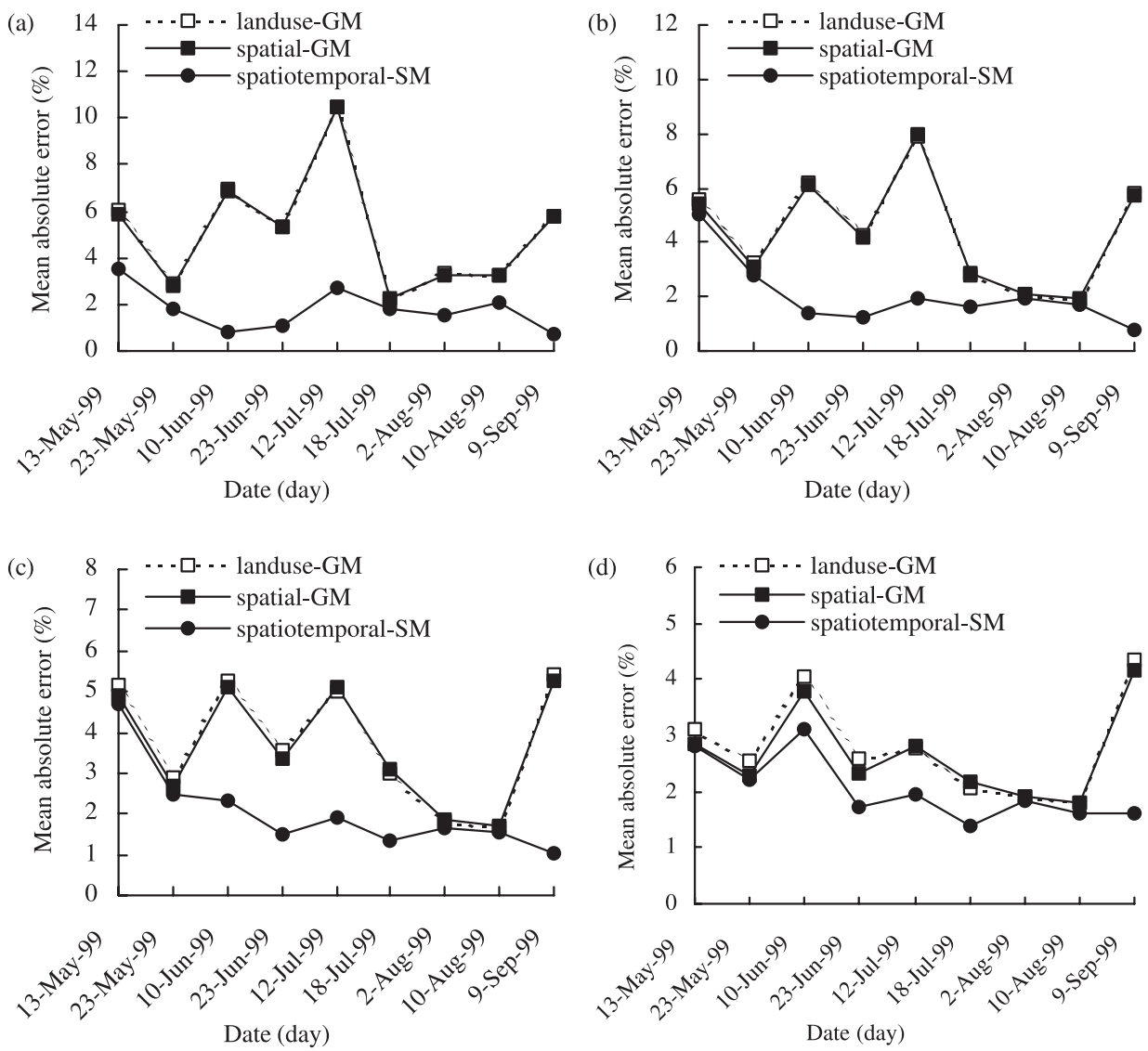

(e) $3.5[-\cdots--$ - landuse-GM
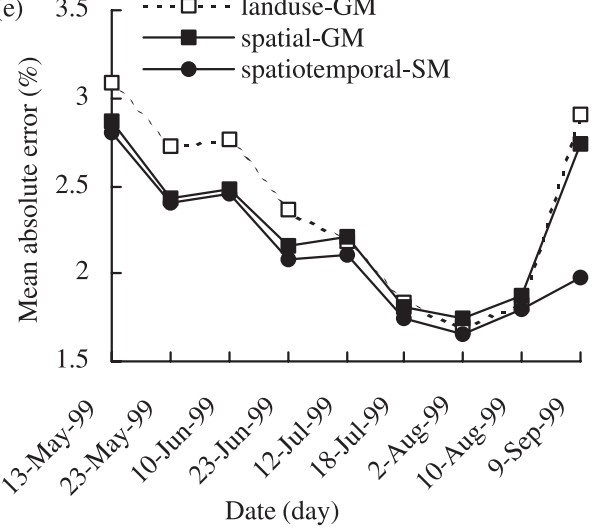

Fig. 8. Mean absolute error of prediction models of soil moisture content at five depths in 1999 (sample is 81). (a) $0-5 \mathrm{~cm}$; (b) $10-15 \mathrm{~cm}$; (c) $20-25 \mathrm{~cm}$; (d) $40-45 \mathrm{~cm}$; (e) $70-75 \mathrm{~cm}$. Note the decreasing scale of the $Y$ axis in a to $\mathrm{e}$. 

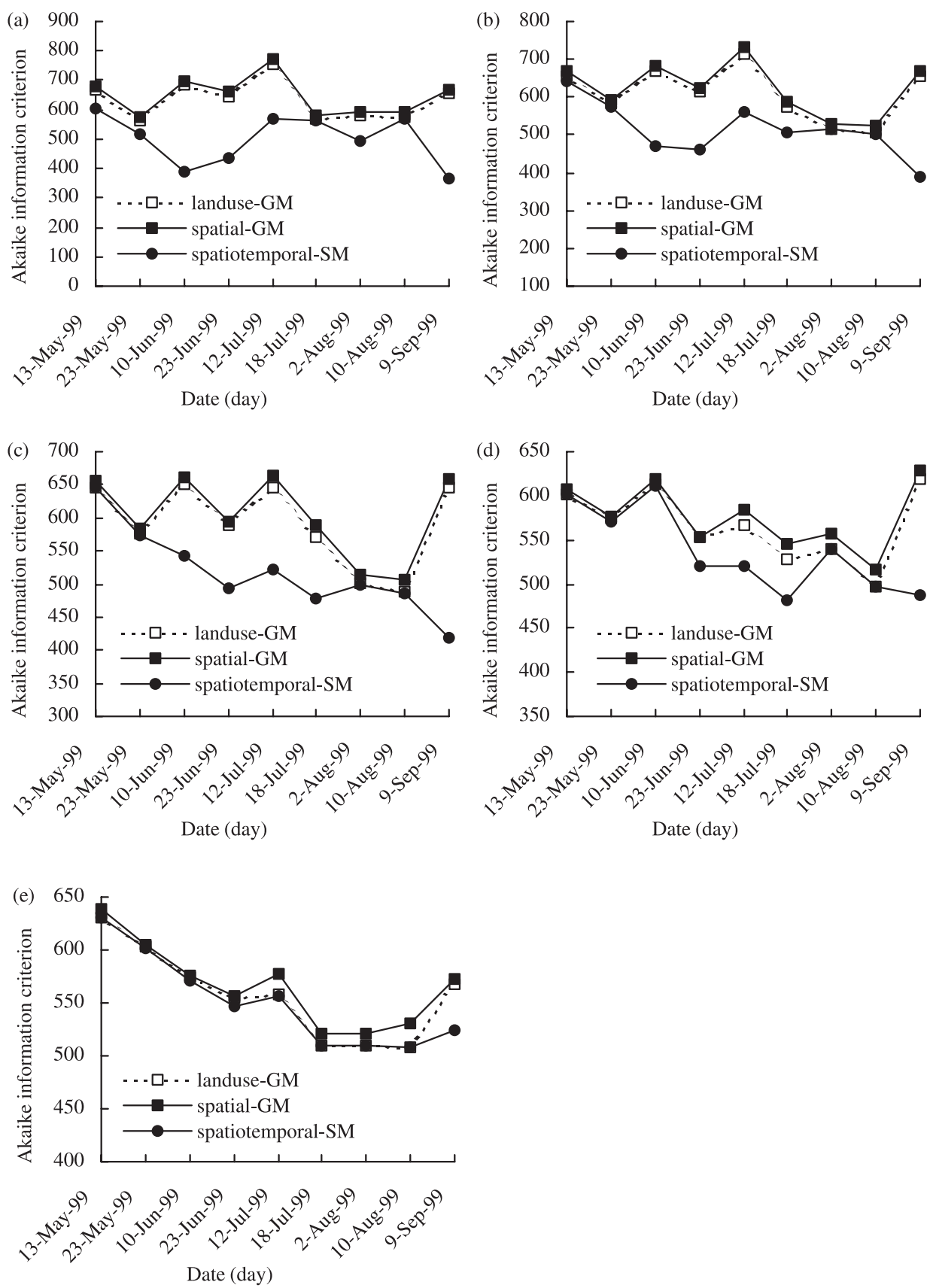

Fig. 9. Akaike information criterion of prediction models of soil moisture at five depths in 1999 (sample is 81). (a) $0-5 \mathrm{~cm}$; (b) $10-15 \mathrm{~cm}$; (c) $20-25 \mathrm{~cm}$; (d) $40-45 \mathrm{~cm}$; (e) $70-75 \mathrm{~cm}$. Note the decreasing scale of the $Y$ axis in a to e. 
The MAE of the spatiotemporal-SM model generally shows lower values than the other two prediction models, and the MAE of the spatial-GM model is generally lower than for the landuse-GM model though the difference is small (Fig. 8). Two sub-periods can be distinguished in the temporal dynamics of the MAE of the spatiotemporal-SM model, with a higher value of the MAE during the sub-period before 23 June 1999 and a lower value in the sub-period after 10 June 1999. Again, this derives from the fact that the measurements from 23 June 1999 and subsequent measurements have been used for the development of the regression models, while those gathered before this date have not. This phenomenon becomes more obvious as soil depth increases. Nevertheless, the overall result indicates the validity of the spatiotemporal-SM model in predicting soil moisture content at any location on any day. As soil depth increases, the MAE of the spatiotemporal-SM model increases while those of the other two models decrease. Therefore, the difference of the MAE between the spatiaotemporal-SM model and the other two prediction models is becoming smaller with increasing depth. The observed soil moisture content displays a significant temporal dynamics while the predicted soil moisture content by both the landuse-GM model and the spatial-GM model are the same for any dates (Fig. 7). Therefore, the MAE values of both the landuse-GM model and the spatial-GM model also show a temporal dynamics, which are to some degree determined by the difference between predicted and observed soil moisture (see Figs. 7 and 8). For example, the MAE of these two models shows relatively low values such as on 23 May 1999, 2 August 1999 and 10 August 1999 since the observed soil moisture is similar to those estimated here. While, the MAE exhibits relatively higher values such as on 13 May 1999, 12 July 1999 and 9 September 1999 when the difference between the observed and predicted soil moisture is greater (see Figs. 7 and 8). Effectively, this means that one should be very cautious when applying these two models to predict soil moisture content for future dates. Such prediction might be possible when the actual soil moisture would be similar to those estimated here.

Fig. 9 indicates that the AIC exhibits the same trend as that of MAE, i.e. the spatiotemporal-SM model is the best in terms of both precision and economy since it has the lowest prediction error and includes not so many independent variables $(10-13)$. The landuse-GM model shows slightly lower values than the spatial-GM model given only 6 independent variables in the former model but 14 in the latter.

In addition, as soil depth increases, both MAE and AIC of all three models get more stable (Figs. 8 and 9). This matches the trend of mean soil moisture (Fig. 7). It implies that the estimation of soil moisture content will be easier at deeper soil depths since there is little temporal fluctuation of soil moisture at these depths.

\section{Summary and conclusions}

Three basic multiple-linear regression models with different sets of more readily observed environmental variables (land use, topography and meteorology) were developed for the prediction of soil moisture distribution in space and time. The model performances were evaluated in the Danangou catchment $\left(3.5 \mathrm{~km}^{2}\right)$ on The Loess Plateau of China. Soil moisture measurements were performed biweekly at five depths in soil profile $(0-5,10-$ 
15, 20-25, 40-45 and 70-75 cm) from May to October 1998 and from May to September 1999 using a Delta-T theta probe based on time domain reflectometry (TDR).

It was found that the prediction models of soil moisture content based on the physical relation between soil moisture and environmental attributes could describe the relationships of soil moisture with environmental attributes.

The landuse-GM model, incorporating spatial variables of land use, can partly account for the spatial variation in soil moisture content. The spatial-GM model, including both land use and topography, improves model performance little. However, the spatiotemporal-SM model can explain much more soil moisture variation in both space and time since it includes both spatial and temporal attributes. As soil depth increases, the amount of variation in soil moisture explained by the landuse-GM model and the spatial-GM model increases, while that of the spatiotemporal-SM model decreases. This relates to the decreasing influence of temporal attributes (meteorological factors) with increasing soil depth.

The spatiotemporal-SM model is both the most precise and the most economical in the prediction of soil moisture content in space and time. The predictions by this model are closer to the observations than the predictions by the other two models. This model has the lowest values of prediction error (MAE) and of the Akaike information criterion (AIC), indicating the lowest bias but also the most economy in prediction of soil moisture. There is little difference in performance and cost-benefit between the spatial-GM model and landuse-GM model. The superior robustness of the spatiotemporal-SM model over the other two models is most significant in the prediction of soil moisture at $0-5 \mathrm{~cm}$, and decreases with increasing soil depth.

\section{Acknowledgements}

The project was funded by the INCO-DC of European Commission (contract no. ERBIC18CT970158) and National Natural Science Foundation of China (contract no. 49725101, 90102018 and 40201003). Thanks are expressed to the member of project team for field assistance, to Rudi Hessel for LISEM assistance and useful comments on drafts of the manuscript, to the Ansai meteorological station for provision of the Meteorological data, and to two anonymous reviewers for useful comments on the paper.

\section{References}

Bourennane, H., King, D., Chery, P., Bruand, A., 1996. Improving the kriging of a soil variables using sloep gradient as external drift. Eur. J. Soil Sci. 47, 473-483.

Brubaker, S.C., Jones, A.J., Frank, K., Lewis, D.T., 1994. Regression models for estimating soil properties by landscape position. Soil Sci. Soc. Am. J. 58, 1763-1767.

Chen, L.D., Messing, I., Fu, B.J., Ledin, S. Land use evaluation and scenario analysis towards sustainable planning on the Loess Plateau in China-case study in a small catchment. Catena 54, 303-316. (doi:10.1016/S0341-8162(03)00071-7)

De Roo, A.P.J., Wesseling, C.G., Jetten, V.G., Ritsema, C.J., 1996. LISEM: a single-event physically based hydrological and soil erosion model for drainages basins: I. Theory, input and output. Hydrol. Process. 10, $1107-1117$.

Fu, B.J., 1989. Soil erosion and its control in the Loess Plateau of China. Soil Use Manage. 5, 76-82. 
Fu, B.J., 1991. Land evaluation in the Loess Plateau of northern Shaanxi province. J. Soil Water Conserv. 5, 1-7 (in Chinese).

Fu, B.J., Chen, L., 2000. Agricultural landscape spatial pattern analysis in the semi-arid hill area of the Loess Plateau, China. J. Arid Environ. 44, 291-303.

Fu, B., Gulinck, H., 1994. Land evaluation in area of severe erosion: the Loess Plateau of China. Land Degrad. Rehabil. 5, 33-40.

Fu, B.J., Chen, L., Ma, K., Zhou, H., Wang, J., 2000. The relationships between land use and soil conditions in the hilly area of the Loess Plateau in northern Shaanxi, China. Catena 39, 69-78.

Fu, B.J., Wang, J., Chen, L., Qiu, Y., 2003. The effects of land use on soil moisture variation in the Danangou catchment of the Loess Plateau, China. Catena 54, 197-213. (doi:10.1016/S0341-8162(03)00065-1)

Georgakakos, K.P., Baumer, O.W., 1996. Measurement and utilization of on-site soil moisture data. J. Hydrol. $184,131-152$.

Hawley, M.E., Jackson, T.J., McCuen, R.H., 1983. Surface soil moisture within a watershed: variations, factors influencing and relationships to surface runoff. Soil Sci. Soc. Am. J. 40, 773-776.

Hessel, R., Jetten, V., Zhang, G., 2003 Estimating Manning's $n$ for steep slopes. Catena 54, 77-91. (doi:10.1016/S0341-8162(03)00058-4)

Hontoria, C., Rodriguez-Murillo, J.C., Saa, A., 1999. Relationships between soil organic carbon and site characteristics in Peninsular Spain. Soil Sci. Soc. Am. J. 63, 614-621.

King, D., Bourennane, H., Isambert, M., Macaire, J.J., 1999. Relationships of the presence of a non-calcareous clay-loam horizon to DEM attributes in a gently sloping area. Geoderma 89, 95-111.

Lark, R.M., 1999. Soil-landform relationships at within-field scales: an investigation using continuous classification. Geoderma 92, 141-165.

Laslett, G.M., McBratney, A.B., Pahl, P.J., Hutchinson, M.F., 1987. Comparison of several spatial prediction methods for soil pH. J. Soil Sci. 38, 325-341.

Legates, D.R., McCabe Jr., G.J., 1999. Evaluating the use of "goodness-of-fit" measures in hydrologic and hydroclimatic model validation. Water Resour. Res. 35, 233-241.

Liu, G., Xu, M., Ritsema, C.J., 2003. A study of soil surface characteristics in a small watershed in the hilly, gullied area on the Chinese Loess Plateau. Catena 54, 31-44. (doi:10.1016/S0341-8162(03)00055-9)

Manrique, L.A., Jones, C.A., Dyke, P.T., 1991. Predicting soil water retention characteristics from soil physical and chemical properties. Commun. Soil Sci. Plant Anal. 22, 1847-1860.

McKenzie, N.J., Austin, M.P., 1993. A quantitative Australian approach to medium and small scale surveys based on soil stratigraphy and environmental correlation. Geoderma 57, 329-355.

McKenzie, N.J., MacLeod, D.A., 1989. Relationships between soil morphology and soil properties relevant to irrigated and dryland agriculture. Aust. J. Soil Res. 27, 235-258.

McKenzie, N.J., Ryan, P.J., 1999. Spatial prediction of soil properties using environmental correlation. Geoderma 89, 67-94.

McKenzie, N.J., Smettem, K.R.J., Ringrose-Voase, A.J., 1991. Evaluation of methods for inferring air and water properties of soil from field morphology. Aust. J. Soil Res. 29, 587-602.

Messing, I., Chen, L.D., Hessel, R., 2003. Soil conditions in a small catchment on the Loess Plateau in China. Catena 54, 45-58. (doi:10.1016/S0341-8162(03)00056-0)

Moore, I.D., Gessler, P.E., Nielsen, G.A., Peterson, G.A., 1993. Soil attribute predictions using terrain analysis. Soil Sci. Soc. Am. J. 57, 443-452.

Nyberg, L., 1996. Spatial variability of soil water content in the covered catchment of Gardsjon, Sweden. Hydrol. Process. 10, 89-103.

Odeh, I.O.A., McBratney, A.B., Chittleborough, D.J., 1994. Spatial prediction of soil properties from landform attributes derived from a digital elevation model. Geoderma 63, 197-214.

Qiu, Y., Zhang, J., 1999. Quantitative analysis to the gradients in space and time of natural plant communities in Bashuigou of the Guandi Mountain. Chin. J. Appl. Environ. Biol. 5, 113-120 (in Chinese).

Qiu, Y., Fu, B., Wang, J., Chen, L., 2000. Quantitative analysis of relationships between spatial and temporal variation of soil moisture content and environmental factors at a gully catchment of the Loess Plateau. Acta Ecol. Sin. 20 (5), 741-747 (in Chinese).

Qiu, Y., Fu, B.J., Wang, J., Chen, L.D., 2001a. Soil moisture variation in relation to topography and land use in a hillslope catchment of the Loess Plateau, China. J. Hydrol. 240 (3-4), 243-263. 
Qiu, Y., Fu, B.J., Wang, J., Chen, L.D., 2001b. Spatial variability of soil moisture content and its relation to environmental indices in a semi-arid gully catchment of the Loess Plateau, China. J. Arid Environ. $49,723-750$.

Robinson, M., Dean, T.J., 1993. Measurement of near surface soil water content using a capacitance probe. Hydrol. Process. 7, 77-86.

Song, G., Li, L., Guo, F., Zhao, M., 1989. Land classification of experiment and exemplary areas on the Loess Plateau, memoir of northwestern institute of soil and water conservation. Acad. Sin., Minist. Water Resour. $10,1-13$ (in Chinese).

Stein, A., Van Dooremolen, W., Bouma, J., Bregt, A.K., 1988. Cokriging point data on moisture deficit. Soil Sci. Soc. Am. J. 52, 1418-1423.

Stolte, J., Van Venrooij, B., Zhang, G., Trouwborst, K.O., Liu, G., Ritsema, C.J., Hessel, R., 2003. Land-use induced spatial heterogeneity of soil hydraulic properties on the Loess Plateau in China. Catena 54, 59-75. (doi:10.1016/S0341-8162(03)00057-2)

Wang, J., Fu, B.J., Qiu, Y., Chen, L.D., 2001a. Soil nutrients variation in relation to land use and topography in gully catchment on Loess Plateau of China. J. Arid Environ. 48, 537-550.

Wang, J., Fu, B.J., Qiu, Y., Chen, L.D., 2001b. Geostatistical analysis of soil moisture variability in space and time on Da Nangou catchment of Loess Plateau, China. Environ. Geol. 41, 113-120.

Wang, J., Fu, B.J., Qiu, Y., Chen, L.D., 2003. Analysis on soil nutrient characteristics for sustainable land use in Danangou catchment of the Loess Plateau, China. Catena 54, 17-29. (doi:10.1016/S0341-8162(03)00054-7)

Webster, R., 1985. Quantitative spatial analysis of soil in the field. Adv. Soil Sci. 3, 1-70.

Webster, R., Butler, B.E., 1976. Soil survey and classification studies at Ginninderra. Aust. J. Soil Res. 14, 1-24.

Webster, R., McBratney, A.B., 1989. On the Akaike Information Criterion for choosing models for variograms of soil properties. J. Soil Sci. 40, 493-496.

Western, A.W., Bloschl, G., Grayson, R.B., 1998. Geostatistical characterisation of soil moisture patterns in the Tarrawarra catchment. J. Hydrol. 205, 20-37.

Western, A.W., Grayson, R.B., Bloschl, G., Willgoose, G.R., McMahon, T.A., 1999. Observed spatial organization of soil moisture and its relation to terrain indices. Water Resour. Res. 35, 797-810.

Willmott, C.J., 1981. On the validation of models. Phys. Geogr. 2, 184-194.

Wu,Y., Xie, K., Zhang, Q., Zhang, Y., Xie, Y., Zhang, G., Zhang, W., Ritsema, C.J., 2003. Crop characteristics and their temporal change on the Loess Plateau of China. Catena 54, 7-16. (doi:10.1016/S03418162(03)00053-5)

Yates, S.R., Warrick, A.W., 1987. Estimating soil water content using cokriging. Soil Sci. Soc. Am. J. 51, 23-30. 